\title{
Research on Effective Strategy for Organizing College Students to Carry out Basketball Training
}

\author{
Shi Wei \\ Puyang Vocational and Technical College, Henan, Puyang, 457000
}

Keywords: Basketball training; college students; strategy

\begin{abstract}
Quality education has put forward new requirements for college basketball training. Basketball training activities should not only promote students' basketball level, but also improve students' comprehensive quality, so as to cultivate more excellent talents. This paper illustrates the necessity and present situation of organizing basketball training activities, and then analyzes the strategies of organizing college students to participate in basketball training activities.
\end{abstract}

\section{Introduction}

In the process of basketball training activities, teachers should pay attention to motivation of students' interests, and scientific nature and rationality of activities, and enable students to positively and actively participate therein. Therefore, college basketball teachers need to update the teaching mode, introduce the teaching modes, such as experiential teaching method, game teaching method and group cooperative teaching method, so that students become interested in basketball training, actively participate therein, and effectively improve their basketball level and comprehensive quality.

\section{Necessity of Organizing Basketball Training Activities}

Basket playing is different from individual competitive sports, such as badminton and table tennis. Strong practice is the main characteristic of basketball teaching, which has high requirements for teamwork. In a basketball game, the game success cannot be guaranteed only relying on skills, and usually requests tacit cooperation between team members ${ }^{[1]}$. Therefore, in the basketball teaching in colleges and universities, the needs for basketball teaching effectiveness can't be satisfied simply by theoretical interpretation and personal skills training. Teachers should realize the importance of basketball training activities, integrate basketball training activities into daily basketball teaching, allow students to enhance team consciousness and cooperative ability when participating in training activities, and improve students' basketball playing ability in colleges and universities on the whole.

In the context of college basketball teaching reform, reform of the basketball training activity mode is inevitable. Basketball teachers in colleges and universities should fully realize to organize a series of rational and feasible training activities for students, strengthen teaching management in the training process, further enhance the effectiveness of basketball training activities, and promote the reform of basketball teaching in colleges and universities. First of all, in basketball training activities, students need to independently participate in practical activities, and not only shall apply the learned basketball knowledge and skills, but also need to mutually cooperate with others. Secondly, in order to achieve victory in basketball games, teachers usually "research and develop" basketball skills, skillfully use "deceptive movement", etc., can not only cultivate students' innovation consciousness and ability, but also cultivate students' sense of competition, so as to help students to form correct sports spirits ${ }^{[2]}$.

Influenced by the factors such as academic pressure, a part of college students have psychological problems, which often cause some painful events, and have become one of the problems attracting attention of the current society and educational circles. Sports and basketball in traditional colleges and universities are too dull to effectively alleviate students' psychological 
pressure. Therefore, colleges and universities should give full play to the functions of basketball teaching, so that students increase communication and interaction between them in the process of participating in training activities, obtain happy emotional experience, release pressure, positively face learning and life, and realize their healthy physical and mental development.

\section{Present Situation of Basketball Training Activities in Colleges and Universities}

At present, the basketball training teaching mode: 1) is "free-ranging", i.e., students are completely free in activities after determining absences before class, where there are a lot of phenomena that most students, especially schoolgirls, have not touched basketball after a basketball class, while the students participating in basketball activities are also "blindly playing" without skills and tactics and with poor basketball training effects; 2) is "strictly managed", i.e., teachers pay too much attention to the competitiveness of basketball teaching, strictly set various game specifications and rules in the training process, compulsively request all students to participate in the same basketball training activities, neglect individual differences of students, and are difficult to achieve ideal training effects ${ }^{[3]}$.

For the basketball exercise, skills and tactics are equally important. In the present college basketball training activities, students do not have clear concepts on basketball rules, often neglect rules, are more unclear about the concept of basketball tactics, will neither arrange tactics before training, nor have perfect offensive and defensive tactics, etc. in the process of training, and are unable to do give play to the basketball skills. The main reason is that in usual training, teachers neglect tactical awareness and skills training and guidance, and pay too much attention to students' independent training, thereby resulting in students' weak tactical awareness, and affecting the quality of training activities.

In basketball training activities, some teachers have not yet been integrated into corresponding teaching methods. The activities are organized with certain randomness and irrationality, and are not only difficult to stimulate students' thirst for participation, but also difficult to ensure smooth implementation of training activities. In the organization of training, teachers usually first explain the theoretical knowledge and skills, then ask students to have independent training, do not participate in students' training activities, are difficult to find students' problems existing in the training process, are also hard to understand students' training process to give specific guidance, and are hard to improve students' basketball level and comprehensive quality by training.

\section{Strategies of Organizing College Students to Participate in Basketball Training Activities}

Teachers should constantly update their concept of PE teaching. First of all, basketball teachers in colleges and universities should establish the teaching idea of "comprehensive development", gradually break through competitive basketball teaching mode, and teach students using diversified basketball teaching modes. Secondly, basketball teachers in colleges and universities should set up the "lifelong learning" teaching idea, and enable the "lifelong learning" idea to run through the entire process of basketball training, so as to provide students with more opportunities for cooperative training, application techniques and tactics ${ }^{[4]}$. Finally, PE teachers in colleges and universities should establish the teaching idea of "quality education", integrate quality education into basketball training activities, attach importance to cultivation of students' comprehensive quality, and cultivate inter-disciplinary talents, so as to improve the effectiveness of college basketball teaching.

Only after feeling interested in basketball training activities, can students positively and actively participate. Therefore, teachers should pay attention to motivation of students' enthusiasm. Sports games are rich in contents and forms, which can stimulate students' interests. Sports games conform to the physiological and psychological characteristics of students in colleges and universities. PE teachers guide students to compete in a happy game atmosphere, so that students get a pleasant emotional experience in the process of competition, so as to positively and actively take part in physical training, and lay the good foundation for smooth implementation of basketball training 
activities.

In a basketball game, tactical awareness and tactical skills are related to the success or failure of the game, while students need to accumulate tactical awareness training in practice. The experiential learning method emphasizes students' personal participation, and can improve students' degree of participation in basket training activities ${ }^{[5]}$. Therefore, in the process of organizing basketball training activities, teachers should actively integrate into the experiential learning method, so that students practice and summarize basketball tactics in the training process, and improve their level of basketball tactics. For example, teachers organize students to watch videos of CBA and NBA with obvious tactical awareness and to study the tactics therein, subsequently request students to apply relevant tactics to games and to communicate and discuss about experience, etc. after the games, enable students to independently participate in the entire process of tactical learning, application and summarization, so as to experience the importance and skills of applying tactics in basketball games, and cultivate students' tactical consciousness.

Basketball playing emphasizes teamwork. Even if an individual has skilled basketball tactics, but lacks team consciousness in team competition, it is still difficult to guarantee for winning the game. Therefore, teachers should pay attention to cultivation of students' team consciousness and good sportsmanship, so as to realize ideal training effects. For example, after explaining the "basketball playing method", a teacher divides students into different groups, asks students in different groups to have different exercises, asks students to cooperate with and help each other in training, strives to ask each member to be skilled in ball handling, carefully observes student training process, finds problems in time, and corrects problems to improve the training effectiveness. In this way, students not only participate in the experience, and master the skills of ball handling in practice, but also can cultivate students' spirit of mutual cooperation and help, and cultivate their team awareness and sense of competition.

After training is completed, teachers should evaluate students correspondingly in encouraging wordings, so that students can feel the sense of accomplishment of participating in basketball training activities, thus enhancing students' confidence in continued training. In addition, in mid-term and final exams, teachers cannot assess student performance simply based on basketball skills, basket shooting accuracy, etc. Teachers can introduce basketball training activities into the teaching evaluation, carefully observe student performance in the training process, and comprehensively evaluate students, thus promoting students' basketball training effects.

\section{Conclusion}

In conclusion, quality education is becoming increasingly more mature, and traditional college basketball training forms no longer apply. Therefore, college basketball teachers should actively change training ideas, integrate sports games, experiential learning methods and the like into basketball training activities, organize a series of flexible, comprehensive and effective basketball training activities, enable students to actively participate therein, and correspondingly guide students, in order to improve students' basketball level and ability, and cultivate students' comprehensive quality.

\section{References}

[1] Li Aichen. Research on Problems and Countermeasures Encountered in the Development of College Basketball Marketization in China [J]. Chinese and Foreign Entrepreneurs, 2015, (32): 256.

[2] Wang Fang. Development Constraints of University Basketball Level and Strategy Study [J]. 2015, 14 (2): 87-88.

[3] Tang Zhenyu, Zhang Yufeng and Dong Yanguo. Empirical Study on the Impact of Different Technological Teaching Strategies on Students' Emotions in University Basketball Course [J]. Journal of Hubei Sports Science, 2013, 32 (3): 259-261. 
[4] Jin Guangzhu. Strategy of Using Basketball Teaching Interest Inducement in Colleges and Universities [J]. Contemporary Sports Technology, 2014, 4 (3): 93-94.

[5] Hu Weidong. Analysis on College Basketball Classroom Teaching Deficient in Ecologicalization and Countermeasures thereof [J]. Practical Electronics, 2013, (9): 172. 